\title{
CONSTRUINDO UM AMBIENTE LABORAL SAUDÁVEL: A INFORMAÇÃO AMBIENTAL TRABALHISTA COMO DIREITO FUNDAMENTAL NA PREVENÇÃO DE DANOS À SAÚDE DO TRABALHADOR.
}

\author{
Rayanny Silva Siqueira Monteiro ${ }^{1}$
}

\begin{abstract}
Resumo:
$\mathrm{O}$ meio ambiente do trabalho, como aspecto do meio ambiente, se refere às circunstâncias a que o homem está exposto enquanto exerce uma atividade laboral. Embora exista um significativo aporte normativo, os dados sobre as agressões à saúde do trabalhador ainda são alarmantes, sendo certo que somente conhecendo as condições de seu ambiente de trabalho poderão compreender melhor os riscos a que estão expostos e os mecanismos para combatêlos. Através da pesquisa exploratória e bibliográfica-documental, com método indutivo e qualitativo, o presente artigo pretende demonstrar a relevância do direito à informação ambiental trabalhista na concretização de um ambiente laboral hígido.
\end{abstract}

Palavras-chave: Direito fundamental; Informação; Meio ambiente do Trabalho; Saúde do Trabalhador; Prevenção.

\section{BUILDING A HEALTHY ENVIRONMENT LABOUR: THE ENVIRONMENTAL INFORMATION LABOR AS FUNDAMENTAL RIGHT IN THE PREVENTION OF OCCUPATIONAL HEALTH DAMAGES.}

\begin{abstract}
:
The environment of work, as an aspect of the environment, as regards the circumstances to which man is exposed while exerting labor activity. Although there is a significant regulatory input, data on the attacks on workers' health are still alarming, given that only by knowing the conditions of your work environment can better understand the risks they are exposed to and the mechanisms to combat them. Through exploratory and bibliografhy-documentary research, with inductive and qualitative method, this paper aims to demonstrate the relevance of the right to labor environmental information in the realization of a healthy work environment.
\end{abstract}

Keywords: Fundamental right; Information; Working Environment; Worker Health; Prevention.

\section{INTRODUÇÃO}

\footnotetext{
${ }^{1}$ Discente do Programa de Pós-Graduação em Direito Ambiental (PPGDA-UEA). Atua como Assessora Jurídica na Secretaria de Estado de Infraestrutura do Amazonas (SEINFRA/AM). É graduada em Direito pela Universidade Federal do Amazonas e em Licenciatura em Biologia pelo Instituto Federal de Educação, Ciência e Tecnologia do Amazonas.
} 
Muito embora seja constituído por um conjunto de condições e fatores (de ordem física, psíquica e social) que exercem influência no desenvolvimento dos seres vivos, o meio ambiente é uno, indivisível. Trata-se de um todo, integrativo e transdisciplinar.

Diante deste caráter uno, o ambiente do trabalho, assim como os demais aspectos do meio ambiente, é apenas um enfoque dado a este último, geralmente para facilitar o estudo de determinado bem ambiental, razão pela qual um dano ao meio ambiente do trabalho inevitavelmente repercutirá no meio ambiente como um todo.

A Constituição Federal de 1988 alçou o meio ambiente do trabalho equilibrado, como aspecto integrante do meio ambiente geral, a direito fundamental de todos os trabalhadores, por estar diretamente ligado ao direito à vida digna.

Contudo, não obstante a legislação brasileira se mostrar avançada em relação ao tema, ainda são assustadores os dados sobre as agressões à saúde do trabalhador no ambiente laboral. O último Anuário Estatístico da Previdência Social demonstra que, durante o ano de 2014, foram registrados no INSS cerca de 704,1 mil acidentes do trabalho, dentre eles, 559 mil com CAT registrada, sendo que, destes últimos, 76,5\% ocorreu por motivo Típico, 20,7\% em acidente de trajeto, enquanto que menos de $3 \%$ foram por doença do trabalho.

Como no meio ambiente do trabalho o bem ambiental imediatamente tutelado é a própria saúde do trabalhador, mister se faz o combate preventivo do dano ambiental que, na maioria das vezes, é irreversível e irreparável.

Sem pretender ignorar a responsabilidade compartilhada (entre Estado, sociedade e empresas) pela defesa do meio ambiente do trabalho imposta pela Carta Magna, este artigo foi desenvolvido partindo-se da premissa de que a tutela preventiva dos danos ao ambiente laboral só alcançará significativo avanço quando os próprios trabalhadores, seus destinatários diretos, passarem a exercer de forma efetiva o seu direito à informação ambiental.

Neste sentido, pretende-se, aqui, demonstrar a relevância do direito a informação ambiental trabalhista no fortalecimento de um ambiente laboral saudável, destacando as hipóteses legais que objetivam garantir o exercício de tal direito. Com o propósito de desenvolver o estudo, foi realizada pesquisa exploratória e bibiográfica-documental, com método indutivo e qualitativo, utilizando-se, substancialmente, a doutrina especializada. 


\section{COMPREENSÃO DO MEIO AMBIENTE DE TRABALHO COMO ASPECTO INTEGRANTE DO MEIO AMBIENTE}

Hanna Arendt (2005, pg.15) estabelece três condições básicas pelas quais a vida foi dada ao homem: labor, trabalho e ação. Na perspectiva da filósofa, o labor se refere às atividades fundamentais do ser humano sobre a natureza como condição da sua própria sobrevivência. O trabalho é a atividade pela qual a matéria pré-existente é modificada em artefatos para bem-estar do próprio homem, a produção da mundanidade estabeleceu a mediação entre o homem e os recursos naturais. A ação é exercida diretamente entre os homens, sem a mediação da matéria, atingindo a esfera pública (política).

Observa-se que pelas características do labor o homem produz apenas o necessário para sua sobrevivência. Já pela atividade do trabalho, o homem constrói um mundo artificial, denominado mundanidade, produzindo artefatos não necessariamente essenciais à vida. Nesse sentido, Antônio Jorge Soares (2008, pg. 25) destaca com propriedade que:

É justamente essa mundanidade que irá converter-se no que os economistas clássicos ingleses, David Ricardo e Adam Smith, chamarão de "excedentes" e, por conseguinte, será a marca do capitalismo industrial, de modo que é pela produção de excedentes que a Revolução Industrial irá proporcionar o sistema internacional de trocas de mercadorias que, por sua vez, irá exigir a presença de mercados constituídos, não de escravos, mas de assalariados, como condição necessária ao advento da economia de mercado. (grifo meu)

Com efeito, como consequência civilizatória da adesão ao trabalho surge o modelo econômico e de produção capitalista, que ainda vivemos atualmente. Este, sem dúvidas, nos trouxe uma gama de serviços, bens e produtos nunca vistos antes. Contudo, em contrapartida, é caracterizado por uma série de fatores que põem em risco todo o meio ambiente, como por exemplo, a exploração irracional dos recursos naturais, a concentração de riqueza, o incentivo ao consumo exacerbado, aumento da desigualdade social e a precarização das relações de trabalho que, em conjunto, vêm provocando enorme desequilíbrio na qualidade de vida sadia preconizada pela Constituição Federal.

Diante dessa realidade, e de todas as suas consequências no decorrer da história, duas grandes tendências foram gradativamente ganhando espaço nos últimos tempos: a proteção do meio ambiente e a busca pela sadia qualidade de vida. 
A Constituição Federal de 1988, refletindo essas preocupações, alçou o meio ambiente à condição de direito fundamental quando, nos termos do art. 225, caput, estabelece que todos têm direito ao meio ambiente ecologicamente equilibrado, bem de uso comum do povo e essencial à sadia qualidade de vida, impondo-se ao Poder Público e à coletividade o dever de defendê-lo e preservá-lo para as presentes e futuras gerações.

Observa-se com certa facilidade que o referido texto constitucional adotou dois objetos para tutelar no que tange à questão ambiental, quais sejam: um imediato que é a qualidade do meio ambiente em todos os seus aspectos, e outro mediato que é a saúde, a segurança e o bem estar do cidadão. Desta maneira, o meio ambiente ecologicamente equilibrado como um direito fundamental de terceira dimensão está diretamente ligado à proteção do direito à vida.

O conceito legal de meio ambiente é previsto na Lei n. ${ }^{\circ} 6.938$, de 31 de agosto de 1981, em seu art. $3^{\circ}$, inciso I, como "o conjunto de condições, leis, influências e interações de ordem física, química e biológica, que permite, abriga e rege a vida em todas as suas formas", o que evidencia o seu caráter unitário. No entender de Paulo Affonso Leme Machado (2006, p. 968) a referida lei definiu o meio ambiente da forma mais ampla possível, fazendo com que este se estendesse à natureza como um todo de um modo interativo e integrativo.

Diante da abrangência dada ao meio ambiente, não resta dúvida que o direito ao meio ambiente ecologicamente equilibrado alcança todos os aspectos que o compõem, nele se incluindo o meio ambiente do trabalho.

Sobre estes aspectos cumpre destacar que, por ser essencialmente uno e indivisível, o meio ambiente não comporta qualquer forma de divisão ou classificação. Isso por que se constitui de seres vivos, elementos abióticos (rios, ventos, prédios, etc), elementos psíquicos (tensões, expectativas, frustrações, etc), bem como de fatores sociais, históricos, culturais, políticos e econômicos que se relacionam entre si, formando uma teia complexa de elementos, integrantes de um todo, que são interdependentes e indissociáveis.

Em razão de todos esses fatores agregarem um caráter interdisciplinar ao meio ambiente, este deve ser analisado de forma holística, sem procurar compartimentar os elementos que o integram. Seu estudo em aspectos se faz necessário apenas para fins 
didáticos, no sentido de conferir-lhe uma proteção mais eficaz na medida em que facilita a identificação da atividade degradante e do bem imediatamente agredido.

Por esta razão, não é terminologicamente adequado aduzir que o meio ambiente do trabalho é uma espécie de meio ambiente. Isso porque espécie possui certa autonomia em relação ao gênero, denota algo fora do todo.

Ainda com relação a estes aspectos do meio ambiente (a saber: natural, artificial, cultural e do trabalho) Norma Sueli Padilha (2002, pg. 32) pontua que:

(...) quando a Constituição Federal, em seu art. 225, fala em meio ambiente ecologicamente equilibrado, está mencionando todos os aspectos do meio ambiente. $\mathrm{E}$, ao dispor, ainda, que o homem para encontrar uma sadia qualidade de vida necessita viver neste ambiente ecologicamente equilibrado, tornou obrigatória também a proteção do ambiente no qual o homem, normalmente, passa a maior parte de sua vida produtiva, qual seja, o do trabalho.

O meio ambiente do trabalho, parte integrante do meio ambiente, está expressamente reconhecido na Carta Magna, possuindo tutela mediata no art. 225, caput, IV e VI e $\S 3^{\circ}$, e imediata no art. 200, VIII, que confia ao Sistema Único de Saúde (SUS) a atribuição de "colaborar na proteção do meio ambiente, nele compreendido o do trabalho".

Apesar de tutelar expressamente o meio ambiente do trabalho no artigo 200, VIII, a Constituição Federal Brasileira não densifica o seu conteúdo, possuindo a doutrina um papel fundamental na construção de seus contornos conceituais.

Não raro nos deparamos com conceitos doutrinários de meio ambiente do trabalho que o vinculam de forma excessiva ao local de trabalho, restringindo-o ao aspecto geográficoespacial. Todavia, a preponderância do local não parece ser a mais adequada.

Isso porque, pelo fato do meio ambiente do trabalho ser um aspecto integrante do ambiente que nos rodeia, o seu conceito não pode escapar ao próprio conceito de meio ambiente, que é considerado como o conjunto de condições (naturais, artificiais, psíquicas, sociais e etc) externas aos seres vivos.

Seguindo neste caminho, o meio ambiente do trabalho se refere, então, às condições que cercam o trabalhador. Trata-se das circunstâncias a que o homem está exposto enquanto exerce uma atividade laboral. 
Tais circunstâncias abrangem diversos fatores como físicos, químicos, biológicos, sociais e psíquicos. Ademais, como a proteção ao meio ambiente do trabalho tutela a saúde do ser humano enquanto trabalhador, estão sob essa tutela todo e qualquer trabalhador que ceda a sua energia de trabalho para benefício de outrem, independente da natureza jurídica da contratação, de vínculo empregatício, ausência de remuneração, idade, gênero etc.

Assim, o habitat laboral envolve não somente o ambiente físico de trabalho, mas também "todo o complexo de relações humanas na empresa, forma de organização do trabalho, sua duração, os ritmos, os turnos, os critérios de remuneração, as possibilidades de progresso, a satisfação dos trabalhadores etc" (OLIVEIRA, 2002, pg. 76).

Neste contexto, merece destaque o entendimento de Adelson Silva dos Santos (2010, pg. 37 ), para o qual o meio ambiente do trabalho não é propriamente um local, pois esta expressão traz uma noção estática. Mais que isso, o conceito de meio ambiente do trabalho não pode deixar de considerar a relação intrínseca com a pessoa humana do trabalhador, visto que lesão ao meio ambiente do trabalho implica necessariamente lesão à saúde do trabalhador. Assim, para o referido autor, a condição da pessoa humana enquanto trabalhadora é que definiria o ambiente laboral.

Tal entendimento parece acertado quando nos atentamos à dificuldade de se identificar determinadas relações de trabalho e mais ainda em se delimitar o local de trabalho tendo em vista a enorme quantidade de trabalhadores que exercem suas atividades de forma irregular, descentralizada ou informal.

Nessa toada, merecem destaque as conclusões de Camargo e Melo (2013, pg. 26):

O meio ambiente do trabalho engloba o espaço e as condições físicas e psíquicas de trabalho, com ênfase nas relações pessoais. O conceito abrange a relação do homem com o meio (elemento espacial de viés objetivo) e a relação do homem com o homem (elemento social de viés subjetivo). Trata-se assim, de uma dinâmica complexa de múltiplos fatores, não se restringindo, somente, a um espaço geográfico delimitado e estático.

Ponto tranquilo na doutrina se refere à natureza jurídica difusa do meio ambiente do trabalho, pois está vinculado diretamente à saúde do trabalhador enquanto cidadão, ou seja, um direito de todos independente da existência de qualquer relação contratual. Desta forma, às normas protetivas do meio ambiente laboral se destinam a todo e qualquer trabalhador seja 
qual for a relação obrigacional (se celetista, servidor público, ou mesmo se inexistir contrato de trabalho), se homem ou mulher, se o serviço é prestado no campo ou cidade etc.

A visão moderna de meio ambiente do trabalho equilibrado ultrapassa a ideia de condições minimamente hígidas para o trabalhador exercer suas atividades no seu posto de trabalho. Hoje, um ambiente laboral equilibrado engloba a ideia de qualidade de vida do trabalhador. Como bem acentua Sebastião Geraldo de Oliveira (2002, pg. 129):

O meio ambiente do trabalho está inserido no meio ambiente geral (art. 200, VII, da Constituição da República), de modo que é impossível alcançar qualidade de vida sem ter qualidade de trabalho, nem se pode atingir meio ambiente equilibrado e sustentável, ignorando o meio ambiente do trabalho. Dentro desse espírito, a Constituição de 1988 estabeleceu expressamente que a ordem econômica deve observar o princípio da defesa do meio ambiente (art. 170, VI)”. (grifo meu)

Dessa forma, como se trata da ambiência onde as pessoas passam a maior parte da sua vida, o meio ambiente do trabalho está diretamente relacionado com a qualidade vida do trabalhador e, por isso, devem ser-lhes garantidas condições mínimas de dignidade.

\section{DIREITO FUNDAMENTAL À INFORMAÇÃO AMBIENTAL}

De acordo com as lições de Canotilho (1993, p. 225-226), o direito à informação tem três níveis: o direito de informar, ou seja, a liberdade de transmitir ou comunicar informações a outrem; o direito de se informar, liberdade de buscar as informações e não ser impedido para tanto; e o direito de ser informado, a versão positiva do direito de se informar, ser mantido informado pelos meios de comunicações disponíveis e pelos poderes públicos.

O direito fundamental à informação, certamente um dos pressupostos básicos ao exercício da cidadania, possui assento em vários dispositivos constitucionais, dentre os quais destaca-se o artigo $5^{\circ}$, XXXIII da Constituição Federal, in verbis:

Art. $5^{\circ}$. Todos são iguais perante a lei, sem distinção de qualquer natureza, garantindo-se aos brasileiros e aos estrangeiros residentes no País a inviolabilidade do direito à vida, à liberdade, à igualdade, à segurança e à propriedade, nos termos seguintes:

(...)

XIV- é assegurado a todos o acesso à informação e resguardado o sigilo da fonte, quando necessário ao exercício profissional;

(...)

XXXIII - todos têm direito a receber dos órgãos públicos informações de seu interesse particular, ou de interesse coletivo ou geral, que serão prestadas no prazo 
da lei, sob pena de responsabilidade, ressalvadas aquelas cujo sigilo seja imprescindível à segurança da sociedade e do Estado;

Ainda, o art. 220 da nossa Carta Magna reforça garantia do exercício do direito à informação:

Art. 220. A manifestação do pensamento, a criação, a expressão e a informação, sob qualquer forma, processo ou veículo não sofrerão qualquer restrição, observado o disposto nesta Constituição.

É de se notar que o princípio da informação está diretamente ligado ao princípio da publicidade ( $\mathrm{CF}$, art. 37, caput) e ao dever de transparência do Estado que, juntos, fortalecem o ideário democrático que fundamenta o Estado de Direito. Parafraseando Celso Antônio Bandeira de Mello (2007, p. 114), "não pode haver em um Estado Democrático de Direito, no qual o poder reside no povo (artigo $1^{\circ}$, parágrafo único, da Constituição), ocultamento aos administrados dos assuntos que a todos interessam, e muito menos em relação aos sujeitos individualmente afetados por alguma medida".

Portanto, a teor do artigo $5^{\circ}$, XXXIII da Carta Magna, todo cidadão tem o direito de receber informações (de interesse particular ou coletivo) requeridas e formuladas perante os órgãos públicos, só se admitindo o sigilo quando imprescindível à segurança da sociedade e do Estado.

Destaque-se que o exercício desse direito sofreu um significativo avanço após a edição da Lei Federal 12.527/2011 (conhecida como lei de acesso à informação), que assegurou o efetivo conhecimento das informações públicas ou contidas em documentos públicos, com as exceções expressamente nela estabelecidas, dentre as quais, o respeito ao direito à privacidade, garantido pelo artigo $5^{\circ}$, inciso $\mathrm{X}$, da Constituição Federal.

A referida Lei informa que os procedimentos nela previstos destinam-se a assegurar o direito fundamental de acesso à informação e devem ser executados em conformidade com os princípios básicos da administração pública e com observância da publicidade como preceito geral e do sigilo como exceção (artigo $3^{\circ}$, I), garantindo, dentre outros, os direitos de obter informação contida em registros ou documentos, produzidos ou acumulados por seus órgãos ou entidades, recolhidos ou não a arquivos públicos; informação sobre atividades exercidas pelos órgãos e entidades, inclusive as relativas à sua política, organização e 
serviços; informação pertinente à administração do patrimônio público, utilização de recursos públicos, licitação, contratos administrativos (artigo $7^{0}$ ).

Segundo Paulo Afonso Leme Machado (2006, p.26), é por meio da informação que se formam novas fontes de saber, e esse é o instrumento que a coletividade utiliza para poder participar, de forma clara, do meio em que vive. Neste sentido, indispensável registrar que o acesso à informação ganha ainda mais destaque quando concernente à seara ambiental, por se tratar de direito difuso, de interesse coletivo.

Encontra-se esteio ao direito à informação ambiental em vários documentos internacionais, bem como na legislação nacional. Para fins de exemplo, destaque-se a Declaração de Estocolmo, em seus Princípios 19 e 20, que reconhece pela primeira vez o significado da informação na relação homem-ambiente. Posteriormente, a Agenda 21 e a Declaração do Rio sobre o meio Ambiente também apresentam dispositivos reafirmando a importância da informação.

O direito à informação ambiental surgiu, portanto, como pressuposto ao exercício do direito ao meio ambiente ecologicamente equilibrado, mas ainda como respeito a um dever jurídico de proteger e preservar recursos desta geração e das futuras (LOURES, 2004, p.198).

No âmbito interno, a Política Nacional do Meio Ambiente (Lei 6.938/1981) estabelece como alguns dos seus instrumentos, nos incisos VII, X e XI, respectivamente, o sistema nacional de informações ambientais, a instituição do Relatório de Qualidade do Meio Ambiente e a garantia da prestação de informações relativas ao meio ambiente, obrigando-se o Poder Público a produzi-las, quando inexistentes.

Paulo Afonso Leme Machado destaca que a informação ambiental, assim como a informação assegurada pela Constituição Federal a todos, deve ser veraz, contínua, tempestiva e completa - itens já conceituados no decorrer da pesquisa. Quanto à informação na sua modalidade ambiental, ela deve, ainda, obedecer aos critérios de tecnicidade, compreensibilidade e rapidez (MACHADO, 2006, p.91).

Tecnicidade porque, em geral a informação ambiental é dotada de dados técnicos, em que constam normas de emissão e padrões de qualidade. Já quanto à compreensibilidade, que não afasta a obrigação de ser clara e compreensível, mesmo possuindo dados técnicos. Ainda, 
deve ser a informação ambiental tempestiva, isto é, rápida e para tanto, é preciso que aquele que transmite a informação seja organizado e eficiente (MACHADO, 2006, p.91-92).

\section{O DIREITO FUNDAMENTAL À INFORMAÇÃO COMO INSTRUMENTO DE PROTEÇÃO DO MEIO AMBIENTE DE TRABALHO}

Preliminarmente, cabe esclarecer que, sabendo-se ser o meio ambiente uno, não se pretende aqui isolar a informação ambiental trabalhista do contexto macro de meio ambiente. Ademais, nem mesmo a informação admite compartimentalização, uma vez que está presente em toda a sociedade, mantendo conexões com os mais diversos elementos sociais, sendo a informação ambiental trabalhista apenas um aspecto daquela mesma informação que estrutura a sociedade informacional.

Pois bem. É inconteste a existência de um número considerável de normas (constitucionais, infraconstitucionais, nacionais e internacionais) que objetivam proteger o meio ambiente do trabalho. Entretanto, como bem disse Sandro Nahmias Melo (2001, pg. 85), uma coisa é o propósito do legislador; outra coisa é a realidade existente.

De fato, no "habitat laboral" o indivíduo está sujeito a diversas agressões que podem vir a causar prejuízos à sua saúde psico-fisiológica. No Brasil, os números referentes a estas agressões são assustadores, mesmo com a deficiência das estatísticas oficiais, que incluem apenas os trabalhadores registrados em carteira ${ }^{2}$. Destaque-se, ainda, que os acidentes de trabalho também geram vultosos gastos ao Sistema Único de Saúde (SUS) e à Previdência Social, além de terem enormes impactos sociais negativos que surgem como efeito cascata.

Diante desta triste realidade, faz-se necessário o estímulo da atuação preventiva mais abrangente no meio ambiente laboral. Não é sem razão, que os preceitos da prevenção e precaução se elevaram a princípios basilares do direito ambiental, uma vez que, após a degradação do meio ambiente, o retorno deste ao status quo ante é, no mínimo, de difícil alcance.

Sem se alongar no debate, é fundamental ressaltar que, apesar de ambos visarem evitar o dano ambiental, são princípios distintos. Assim, pelo princípio da prevenção busca-se evitar danos ambientais já determinados, ou seja, com o nexo causal decorrente da lógica ou

\footnotetext{
${ }^{2}$ Isso significa que expressiva parte da classe trabalhadora do país, incluindo profissionais autônomos, empregadores, militares e estatutários (além de empregados e trabalhadores domésticos informais), não está contemplada nas estatísticas acidentárias da Previdência.
} 
já provado cientificamente. Já pelo princípio da precaução, mesmo não havendo comprovação científica da possível ocorrência do dano ambiental é necessário que se tomem medidas gerais de caráter acautelatório. Basta a possibilidade do risco. Nas palavras de Derani (1997, p. 169): precaução é cuidado (in dubio pro securitate).

Sobre o tema, vale colher ainda a lição de Marcelo Abelha Rodrigues (2005, p. 207) para o qual "enquanto a prevenção relaciona-se com a adoção de medidas que corrijam ou evitem danos previsíveis, a precaução também age prevenindo, mas antes disso, evita-se o próprio risco ainda imprevisto".

No ambiente do trabalho a prevenção dos danos torna-se ainda importante tendo em vista que o bem ambiental a ser imediatamente protegido é a própria saúde do trabalhador. Nesse sentido, mister se evitar que a "disseminação da perversa lógica do descarte seja aplicada ao próprio ser humano no ambiente de trabalho" (GEMIGNANI et. al., 2012, pg. 271).

O ideal preventivo no meio ambiente do trabalho - que depende, antes de tudo, do desenvolvimento de uma consciência ambiental - deve ser concretizado pela atuação integrada de todos os atores envolvidos (Estado, empresas, fabricantes, fornecedores, sociedade, trabalhadores, etc).

Não obstante o Brasil possuir um arcabouço teórico-legislativo satisfatório no assunto, em regra, até mesmo por questões culturais, a prevenção ainda não se tornou prioridade para as empresas e nem, infelizmente, para o próprio profissional, que aparentemente se interessa mais pela defesa de cláusulas de natureza econômica imediata, como por exemplo, reajustes salariais.

Nesse ponto, tendo em vista que no ambiente laboral o bem ambiental imediatamente tutelado é a própria saúde do homem enquanto trabalhador ganhou-se corpo a ideia de que o trabalhador precisa ser informado sobre "os riscos a que está exposto, às formas de prevenção e o treinamento adequado para o desempenho das suas atividades" (OLIVEIRA, 2002, pg. 110).

Dessa forma pode-se exprimir que a efetiva prevenção dos riscos ambientais laborais - sem desejar ignorar os outros fatores - envolve principalmente a garantia do direito à informação ambiental trabalhista. 
Sobre a aplicação do direito à informação no ambiente de trabalho, Júlio Cesar da Rocha Sá (1997, pg. 58) afirma que:

Os trabalhadores têm direito de conhecer as reais condições ambientais que estão expostos (os agentes tóxicos, os níveis de ruído, as altas temperaturas, as radiações, os vapores, etc), bem como a própria forma de organização do trabalho (jornadas noturnas e em turnos, ritmo de trabalho, sua forma de execução e divisão).

Nesse mesmo sentido, Adelson Silva dos Santos (2010, pg. 138-139) assevera que o conteúdo essencial do direito fundamental ao meio ambiente do trabalho hígido exige acesso à informação ao trabalhador, em particular, e à sociedade em geral. Enquanto direito do trabalhador, a informação é dever precípuo do empregador. Contudo, não só o empregador tem o dever de informar, o Estado com mais razão deve promover programas de saúde do trabalhador que garanta informações aos exercentes de atividade laboral quanto aos riscos ambientais.

No ambiente laboral a informação ambiental estimula o processo produtivo em consonância com a preservação dos recursos naturais, mas acima de tudo, com respeito à dignidade humana do trabalhador. Conhecendo as condições de seu ambiente de trabalho os trabalhadores poderão compreender melhor os riscos a que estão expostos e os mecanismos para combatê-los.

\section{PRINCIPAIS PREVISÕES NORMATIVAS CONCERNENTES AO ACESSO À INFORMAÇÃO AMBIENTAL TRABALHISTA}

Como visto, o direito à informação ambiental, como direito fundamental, tem acentuada importância no meio ambiente do trabalho, pois neste caso a própria vida do trabalhador está em risco, devendo o mesmo estar ciente de todos os riscos ambientais que está exposto, o que o proporcionará elementos para uma maior participação na higidez do ambiente laboral.

Enquanto direito fundamental do trabalhador, a informação é dever do empregador. Nesse mesmo sentido, o artigo 19, $\S 3^{\circ}$ da Lei 8.213/91, que dispõe sobre os Planos de Benefícios da Previdência Social e dá outras providências, estabelece que é dever da empresa prestar informações pormenorizadas sobre os riscos da operação a execução e do produto a manipular. 
Notadamente, a Consolidação das Leis Trabalhistas (CLT) contêm relevantes dispositivos acerca da informação ambiental trabalhista:

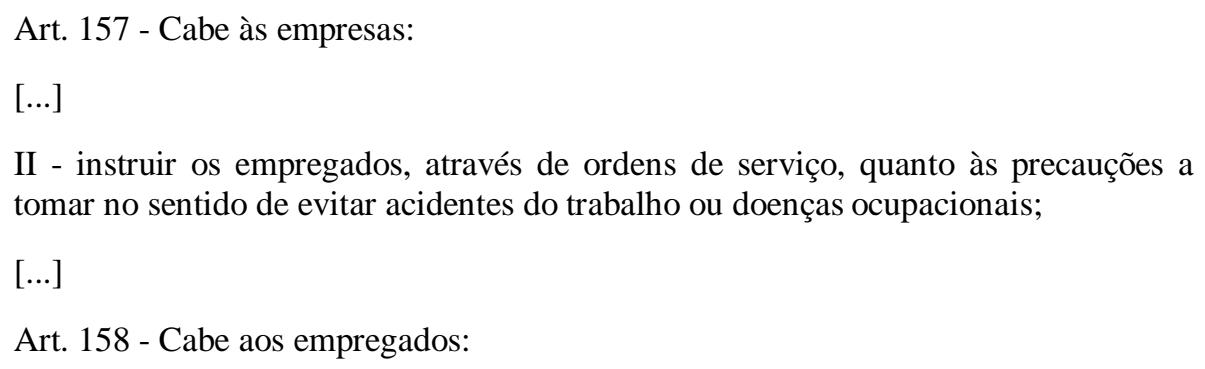

I - observar as normas de segurança e medicina do trabalho, inclusive as instruções de que trata o item II do artigo anterior;

$[\ldots]$

Art. 200 - Cabe ao Ministério do Trabalho estabelecer disposições complementares às normas de que trata este Capítulo, tendo em vista as peculiaridades de cada atividade ou setor de trabalho, especialmente sobre:

$[\ldots]$

VIII - emprego das cores nos locais de trabalho, inclusive nas sinalizações de perigo.

A CLT prescreve ainda, em seus artigos 182, III e 197, obrigações do empregador quanto as informações sobre substâncias e materiais perigosos ou nocivos à saúde utilizados no local de trabalho.

As Normas Regulamentadoras (NR) do Ministério do Trabalho e Emprego também externalizam em seu bojo alguns aspectos do direito a informação ambiental. Por meio destas NR's, em especial NR 1, 5 e 9, podemos extrair certas obrigações do empregador concernentes ao direito de informação do trabalhador. Assim, cabe ao empregador informar aos trabalhadores os riscos profissionais, os meios de prevenção, os resultados de exames a que foram submetidos e das avaliações ambientais realizadas no local da prestação de serviços.

As Comissões Internas de Prevenção de Acidentes (CIPAS), previstas na NR 5, surgem como importantes aliados na disseminação da informação ambiental trabalhista, pois tem como objetivo observar e relatar condições de risco nos ambientes de trabalho e solicitar medidas para reduzir ou até eliminar os riscos existentes e/ou eliminar os mesmos.

Uma importante atribuição da CIPA neste sentido é o desenvolvimento, em colaboração com o Serviço Especializado em Engenharia de Segurança e Medicina do 
Trabalho (SESMT), após ouvidos os trabalhadores de todos os setores, do Mapa de Riscos Ambientais a fim de identificar todos os riscos existentes no ambiente de trabalho para somente assim dar a publicidade e informações devidas aos trabalhadores.

Já a NR 9, que trata do Programa de Prevenção dos Riscos Ambientais (PPRA), dispõe sobre obrigações tanto do empregador, que deve informa aos empregados sobre os riscos laborais existentes e as formas de preveni-los, quanto dos empregados, que têm a responsabilidade de informar seu superior hierárquico direto das ocorrências que entender implicar riscos à sua saúde, como também o direito de apresentar propostas para se evitar riscos ambientais identificados na execução do PPRA.

Os exames médicos periódicos também se constituem formas de representação do direito a informação ambiental trabalhista, pois apresentam caráter orientador. A CLT (art. 169 e 169) e a NR 7 (que trata do Programa de Controle Médico de Saúde) determinam a realização de exames biológico no momento da admissão, periodicamente e na demissão. Dessa forma, os trabalhadores têm garantido seu direito de ser informado sobre as condições de sua saúde no ambiente de trabalho.

O dever de informar não se limita a empregador, também cabe ao Estado promover a informação ambiental (através de programas de saúde do trabalhador, da atuação mais efetiva do Poder judiciário e do Ministério Público do Trabalho) e ao próprio empregado e sindicatos $^{3}$, obedecendo à responsabilidade compartilhada na proteção e defesa do meio ambiente imposta pelo art. 225, caput, da Constituição Federal.

Sobre a atuação Estatal na concretização do direito à informação ambiental no ambiente laboral, prevê a Lei n. 8.080/1990, regulamentadora do Sistema Único de Saúde (SUS), em seu art. $6^{\circ}, \mathrm{I}$, 'c'$\S 3^{\circ}, \mathrm{V}$ :

Art. $6^{\circ}$ Estão incluídas ainda no campo de atuação do Sistema Único de Saúde (SUS):

I - a execução de ações:

\footnotetext{
${ }^{3}$ À despeito da atuação dos próprios trabalhadores na higidez ecológica do local de trabalho, salienta-se que, não obstante muito se discutir na doutrina sobre o papel de alguns legitimados - como o Sistema Único de Saúde e o Ministério Público - na defesa do meio ambiente do trabalho, pouco destaque se tem dado à atuação dos próprios trabalhadores, organizados em sindicatos, na defesa do seu ambiente laboral. Nessa esteira, Sebastião Geraldo de Oliveira (2002, p. 239) afirma que o papel das entidades sindicais no combate às agressões ao ambiente laboral cresce de importância com a tendência moderna de valorizar a autonomia privada coletiva, deixando amplo espaço para os próprios atores sociais.
} 
$[\ldots]$

c) de saúde do trabalhador;

$[\ldots]$

$\S 3^{\circ}$ Entende-se por saúde do trabalhador, para fins desta lei, um conjunto de atividades que se destina, através das ações de vigilância epidemiológica e vigilância sanitária, à promoção e proteção da saúde dos trabalhadores, assim como visa à recuperação e reabilitação da saúde dos trabalhadores submetidos aos riscos e agravos advindos das condições de trabalho, abrangendo:

$[\ldots]$

$\mathrm{V}$ - informação ao trabalhador e à sua respectiva entidade sindical e às empresas sobre os riscos de acidentes de trabalho, doença profissional e do trabalho, bem como os resultados de fiscalizações, avaliações ambientais e exames de saúde, de admissão, periódicos e de demissão, respeitados os preceitos da ética profissional;

No contexto internacional, refletindo a importância deste direito à proteção do meio ambiente laboral hígido, as três principais Convenções Internacionais da Organização Internacional do Trabalho (OIT) sobre saúde do trabalhador fazem referência ao direito a informação.

Assim, a Convenção 148 prevê que "os trabalhadores ou seus representantes terão direito a apresentar propostas, receber informações e orientação, e a recorrer a instâncias apropriadas, a fim de assegurar a proteção contra riscos profissionais devidos à contaminação do ar, ruído e às vibrações no local de trabalho" e ainda que "todas as pessoas interessadas deverão ser suficientemente informadas sobre os riscos profissionais que possam originar-se no local de trabalho".

A Convenção 155, por sua vez, estabelece que os trabalhadores e seus representantes na empresa devem receber treinamento apropriado no âmbito da segurança e higiene no trabalho (art. 19, alínea “d”). Na mesma esteira a Convenção 161 prescreve, no artigo 13, que todos os trabalhadores devem ser informados dos riscos para a sua saúde inerentes ao seu trabalho.

Ainda no plano internacional, destaca-se a Agenda 21 que, no capítulo vinte e nove, ao tratar sobre o fortalecimento do papel dos trabalhadores e de seus sindicatos, estabeleceu entre os objetivos para o século XXI, a redução de acidentes típicos e doenças do trabalho e o aumento da oferta de capacitações em saúde e segurança no meio ambiente do trabalho. 


\section{CONCLUSÃO}

Por todo o exposto, verifica-se que o direito a informação possui significativa previsão normativa (internacional e pátria) na seara ambiental e sua concretização e consequentes reflexos no âmbito do meio ambiente do trabalho vêm ganhando cada vez mais espaço.

Entretanto, sua concretização no plano fático ainda não ocorre da forma desejável, sendo certo que existem instrumentos legais que visam garantir o direito de informação do trabalhador, mas que não vem sendo efetivamente aplicados.

Como aspecto do meio ambiente, direito difuso, o meio ambiente do trabalho não pode ser considerado como propriedade do empregador. Nesse sentido, faz-se necessária a construção da consciência no trabalhador sobre a necessidade de preservação e adequação do seu ambiente laboral. E para a construção dessa consciência é preciso que primeiramente este trabalhador tenha acesso às informações sobre os riscos e condições a que está exposto e de tudo que se relaciona a sua saúde e segurança. Ocorre que a informação, em regra, é dominada pelos detentores dos meios de produção, e nem sempre os alcança.

Somente através da efetivação do direito a informação é que se pode falar em participação mais proativa do trabalhador, assumindo sua parcela de responsabilidade na preservação do meio ambiente do trabalho e, consequentemente, na proteção da sua própria vida.

\section{REFERÊNCIAS}

ARENDT, H. A condição humana. 10ª edição. RJ: Forense Universitária, 2005.

BRASIL. Constituição da República do Brasil. Brasília, DF: Senado Federal, 1988. Disponível em:

$<$ http:// www.planalto.gov.br/ccivil_03/constituicao/ConstituicaoCompilado.htm >. Acesso em: 20 de setembro de 2016.

Decreto-Lei $n$. 5.452, de $1^{o}$ de maio de 1943. Aprova a Consolidação das Leis do Trabalho (CLT). Rio de Janeiro, 1943. Disponível em: <http://www.planalto.gov.br/ccivil_03/decreto-lei/Del5452.htm>. Acesso em: 20 de setembro de 2016. 
Lei n. 6.938, de 31 de agosto de 1981. Dispõe sobre a Política Nacional do Meio Ambiente, seus fins e mecanismos de formulação e aplicação, e dá outras providências. Brasília, 1981 Disponível em:

http://www.planalto.gov.br/ccivil_03/Leis/L6938compilada.htm>. Acesso em: 25 de setembro de 2016.

Ministério do Trabalho e Emprego (MTE). Portaria n. 3.214, de 8 de junho de 1978. Aprova as Normas Regulamentadoras - NR - do Capítulo V, Título II, da Consolidação das Leis do Trabalho, relativas a Segurança e Medicina do Trabalho. Brasília, 1978. Disponível em: http://portal.mte.gov.br/data/files/FF8080812BE914E6012BE96DD3225597/p_19780608_32 14.pdf>. Acesso em: 20 de setembro de 2016.

CAMARGO, Thaísa Rodrigues Lustosa.; MELO, Sandro Nahmias. Princípios de Direito Ambiental do Trabalho. São Paulo: LTr, 2013.

CANOTILHO, J. J. Gomes; MOREIRA, Vital. Constituição da República Portuguesa Anotada. 3. ed. rev. Coimbra: Coimbra Editora, 1993.

DERANI, Cristiane. Direito Ambiental Econômico. São Paulo: Max Limonad, 1997.

GEMIGNANI, Daniel e GEMIGNANI, Tereza A. A. G. Meio ambiente de trabalho. Precaução e prevenção. Princípios norteadores de um novo padrão normativo. Rev.TST, Brasília, vol. 78, no 1, jan/mar 2012.

LOURES, Flavia Tavares Rocha. A implementação do direito à informação ambiental, Revista de Direito Ambiental, São Paulo, Ano 9, n.34, abril/junho 2004.

MACHADO, Paulo Affonso L. Direito Ambiental Brasileiro. 14 ed. São Paulo: Malheiros, 2006. 
MACHADO, Paulo Afonso Leme. Direito à informação e meio ambiente. São Paulo: Malheiros Editores, 2006.

MELlO, Celso Antonio Bandeira de. Curso de Direito Administrativo. São Paulo: Malheiros, 2007.

MELO, Raimundo Simão de. Dignidade da pessoa humana e meio ambiente do trabalho. B. C. da Esc. Sup. do MPU, Brasília, a.4, n.14, p. 87-108 - jan./mar. 2005.

MENEGAZZI, Piero Rosa. A efetivação do direito à informação no meio ambiente do trabalho: contribuições do pensamento sistêmico da teoria da complexidade e do estudo dos riscos. São Paulo: LTr, 2011.

MILARÉ, Edis. Direito Ambiental. Doutrina, Prática, Jurisprudência, Glossário.50ª ed. São Paulo, Revista dos Tribunais, 2007.

NAHMIAS MELO, Sandro. Meio Ambiente do Trabalho: Direito Fundamental, SP: Ltr, 2001 .

OLIVEIRA, Sebastião Geraldo. Proteção jurídica à saúde do trabalhador. 4. ed. SP: LTr, 2002 .

ORGANIZACAO INTERNACIONAL DO TRABALHO. Convenção $n$. 148 - Meio Ambiente do Trabalho (ruído e vibrações). Disponível em: <http://www.mte.gov.br/legislacao/convencoes/cv_148.asp>. Acesso em 21 de setembro de 2016.

Convenção $\quad$ n. $155 \quad-$

Segurança e saúde dos trabalhadores. Disponível em: $<$ http://www.mte.gov.br/legislacao/convencoes/cv_155.asp>. Acesso em 21 de setembro de 2016. Convenção n. 161 - Serviços de saúde no trabalho. Disponível em: <http://www.mte.gov.br/legislacao/convencoes/cv_161.asp>. Acesso em 23 de setembro de 2016.

PADILHA, Norma Sueli. Do meio ambiente do trabalho equilibrado. São Paulo: LTr, 2002. 
ROCHA, Júlio Cesar de Sá da. Direito ambiental e meio ambiente do trabalho: dano, prevenção e proteção jurídica. São Paulo: LTr, 1997.

RODRIGUES, Marcelo Abelha. Elementos de Direito Ambiental. Parte geral. São Paulo: RT, 2005.

SANTOS, Adelson Silva dos. Fundamentos do direito ambiental do trabalho. São Paulo: LTr, 2010.

SOARES, Antônio Jorge. Uma Concepção de Meio Ambiente. Revista da ESMARN Mossoró - v. 8, n. 1, p. 23 - 30 - jan/jun 2008. 